\title{
Improving the Residual Resistivity of Pure Gold
}

\author{
Manfred Poniatowski and Axel Wirths \\ degussa, Hanau, West Germany
}

The achievement of exceptionally high purity in gold necessitates extreme care not only in refining but also in subsequent rolling and drawing. This paper describes the precautions adopted to produce extremely high purity gold, as measured by its residual resistivity ratio.

The production and subsequent working of high purity metals is of continuing and increasing importance due to the demands made by the advanced technology industries. In particular the electronics industry, with a requirement for high performance and reliability, has a specific interest in both pure silver and pure gold. The work presented here was undertaken to establish economic methods of producing pure gold, in a variety of forms, on a commercial scale.

When refining gold bearing ores, the final purification on a commercial basis is almost always carried out either by the Wohlwill electrolytic method or the Miller process. In addition to these two commercial processes there are two laboratory methods, preferred by analytical chemists, whereby gold is separated from a large number of impurities either by ion exchange $(1,2,3)$ or by the extraction of $\mathrm{Au}(\mathrm{III})$ from a chloride solution with various organic solvents $(4,5)$. The modest capacity of the exchangers means, however, that this method is likely to remain exclusively for laboratory use. On the other hand, the liquid-liquid extraction process is definitely of commercial interest due, in part, to the very high coefficient of distribution for gold $(6,7)$.

During the work reported, 0.5 molar $\mathrm{Au}(\mathrm{III})$ in in $\mathrm{HCl}$ doped with $1000 \mathrm{ppm}$ each of a number of impurities typically found in gold was extracted with diethyleneglycoldibutylether (Dibutyl-carbitol) and reduced to elemental gold with oxalic acid. The impurities both in the organic gold solution and in the reduced metal were determined by quantitative spectrographic analysis. The results are given in Table I where, for greater clarity, the limits of detection are included.

The separation of a number of elements during extraction with Dibutyl-carbitol was more thoroughly investigated with the aid of radio-tracers. The elements used were silver, arsenic, copper, iron, mercury, palladium and scandium (instead of aluminium) in amounts of 1,10 and $100 \mathrm{ppm}$. The gamma ray spectra (2000 channels per spectrum) were recorded by a $3^{\prime \prime} \times 3^{\prime \prime} \mathrm{NaJ}(\mathrm{T} 1)$ Well Type Gamma Ray Detector and the distribution of the radio-tracers determined in both phases. Table II gives $T_{F}$, the separation factors-that is the concentration of the element in the aqueous phase compared to the concentration of the element in the organic phase-for individual elements. It can be seen that the $T_{F}$ values for some of the elements are concentration-related.

\section{Sample Preparation}

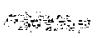

Following the oxalic acid reduction process the resulting gold sponge was melted in a high purity graphite crucible. When the casting skin had been

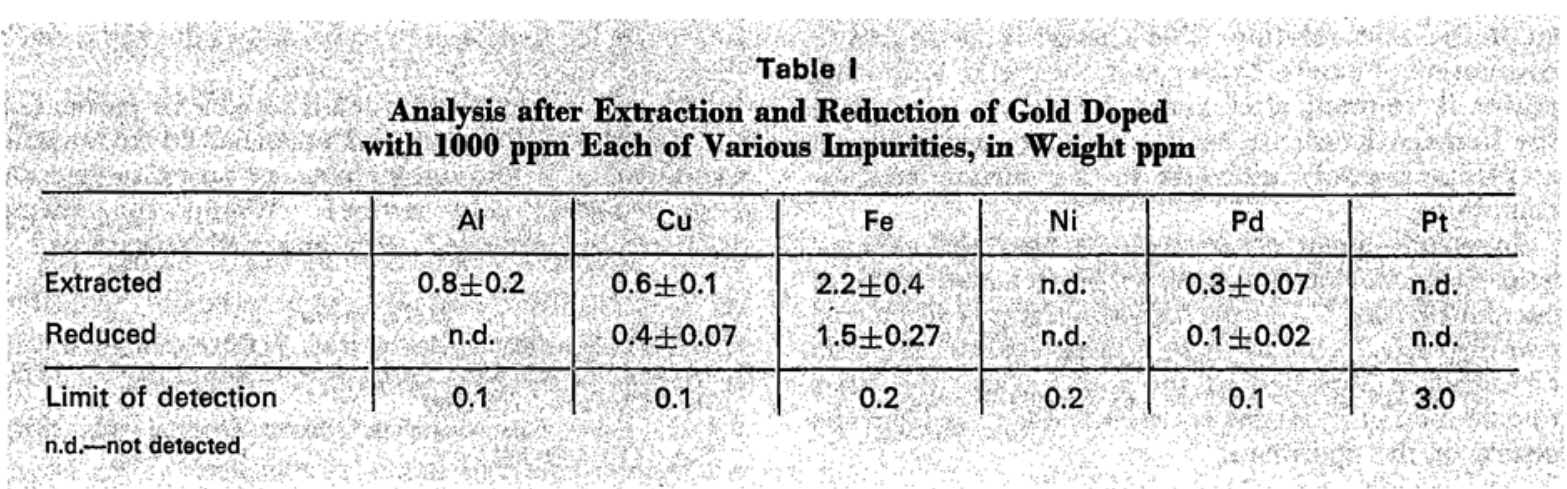


Table II

Separation Factors of the Radio-trace Method

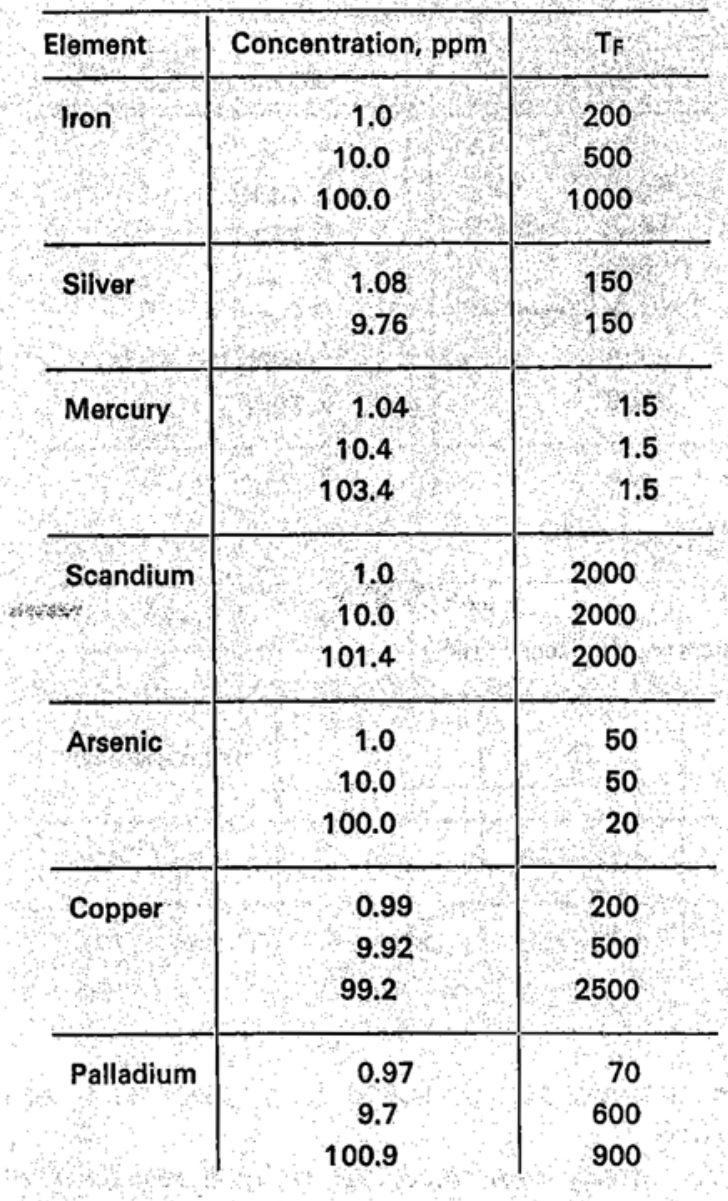

machined from the ingots they were pickled in dilute aqua regia.

After the rolls had been degreased and cleaned one of the gold ingots was put through the rolling mill. This resulted in further cleaning of the rolls, and the deposition of a fine gold film in some places. The proper samples were then rolled down from $5 \mathrm{~mm}$ to 200 microns without interannealing. Without cleaning the rolls again, a proportion of the material was reduced to 30 microns to enable the effects of possible contamination on the residual resistivity to be determined. Table III lists the impurities of the two foils determined by spectrographic analysis.

\section{Measuring the Residual Resistivity}

The degree of purity of a metal is normally quoted in terms of the residual resistivity ratio (RRR), that is to say the ratio of specific resistance at $293 \mathrm{~K}$ and 4.2K. The residual resistivity $\left(\rho_{4 \cdot 2}\right)$ is caused by the scatter of conduction electrons in the vicinity of impurities, lattice defects and the surface of samples. It is possible to diminish the influence of most impurities by controlling the annealing process in an oxidising atmosphere, and that of the lattice defects by slow cooling.

After degreasing and pickling, the foils were annealed in a quartz tube at 900 and $1000^{\circ} \mathrm{C}$ in air and slowly cooled to room temperature over a period of about 10 hours. To obtain the highest possible residual resistivity ratio, annealing times were varied between 1 and 40 hours, see Table IV.

The residual resistivity ratio increases with temperature. Time dependence is measured against a standard temperature of $1000^{\circ} \mathrm{C}$. Figures 1 and 2 show the results for the 200 micron and the 30 micron thick foils. As can be seen from the Figures, looked at in conjunction with Table IV, both thicknesses exhibit an initial rise in RRR which reaches saturation point after an annealing time of about 20 hours.

\section{Discussion of Results}

Since oxygen is virtually insoluble in gold (8) the impurities are not eliminated from the lattice by internal oxidation as is the case with silver, instead they diffuse towards the surface where they become oxidised.

Table V shows the increase in specific resistance calculated from the test results, Table III, and the known increase in atomic resistance (9) caused by individual impurities.

Based on the overall increase in resistance, given in the right hand column of Table V, the RRR for the thicker foil works out at 141 and that for thinner foil

Table III

Contamination of Gold Foil, in Weight ppm

\begin{tabular}{|c|c|c|c|c|c|c|}
\hline $\begin{array}{l}\text { Foil } \\
\text { Thickness, } \\
\text { Microns }\end{array}$ & $\mathrm{Ag}$ & $A \mathrm{~A}$ & $\mathrm{Cu}$ & $\mathrm{Fol}_{\mathrm{o}}$ & $\mathbf{N i}$ & $\begin{array}{l}\text { Sum of the } \\
\text { Impurities }\end{array}$ \\
\hline 200 & $80 \pm 3.4$ & $0.95 \pm 0.4$ & $2.1 \pm 0.5$ & $5.1 \pm 13$ & n.d. & $16,15 \pm 5,6$ \\
\hline 30 & $8.0 \pm 3.4$ & $40+17$ & $46 \pm 1,1$ & $21,0 \pm 5.4$ & $0.93 \pm 0.2$ & $38.53 \pm 118$ \\
\hline
\end{tabular}


Table IV

Residual Resistivity Ratio for Two Foils After Varying Annealing Treatments

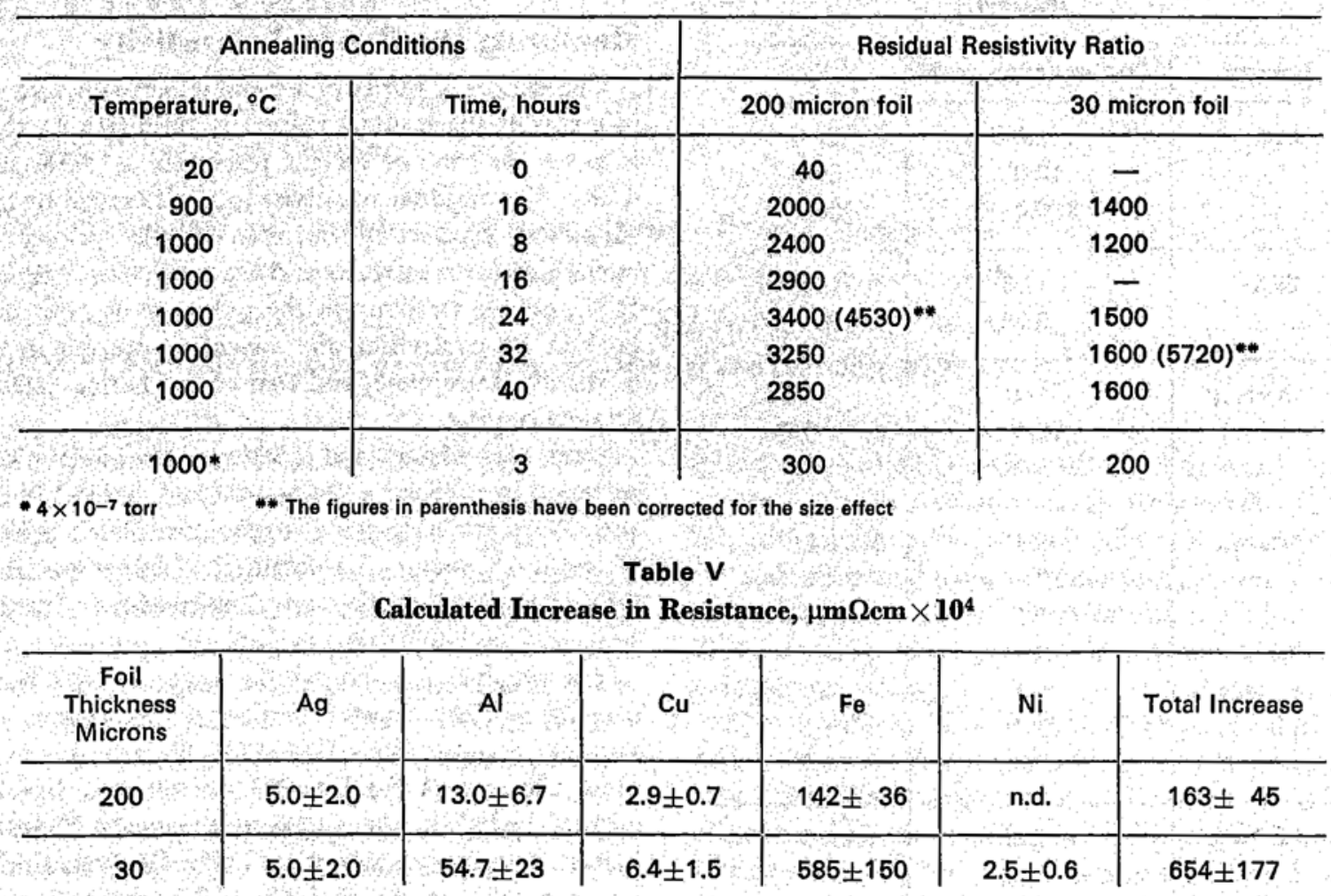

at 35 , showing qualitative agreement with test data.

Since approximately 90 per cent of the increase in resistance is caused by iron, the dependence of RRR on annealing time is likely to be determined in the first phase by the amount of iron diffusion.

The concentration of an element is given with adequate accuracy, and disregarding minor terms, by (10):

$$
c=\left(8 c_{o} / \pi^{2}\right) \exp \left(-\pi^{2} D(T) t / d^{2}\right)
$$

where $c_{o}$ is initial concentration, $d$ is foil thickness, $t$ is annealing time and $T$ is temperature.

The coefficients of diffusion of the elements under consideration at $1000^{\circ} \mathrm{C}(11)$ are shown in Table VI.

Assuming that the diffusion of impurities to the surface is assisted by simultaneous oxidation, no depletion of silver can be expected at an annealing temperature of $1000^{\circ} \mathrm{C}$ since $\mathrm{Ag}_{2} \mathrm{O}$ is unstable at that temperature. Nor is the metal likely to vaporise since at a concentration of $5 \mathrm{ppm}$ the partial pressure according to (8) is less than $5 \times 10^{-8}$ torr.

In conjunction with Table VI and the $c_{o}$ values of Table III, the equation above provides the basis for calculating the concentrations $c$, and from these the increase in specific resistance as a function of time are obtained and presented in Tables VII(a) and VII(b).

As already mentioned, the residual resistivity of thin foil is basically limited by electron scatter at the surface of the sample. According to (12) the figure is $1.7 \times 10^{-4} \mu \mathrm{m} \Omega \mathrm{cm}$ for a thickness of 200 microns, and $10.4 \times 10^{-4} \mu \mathrm{m} \Omega \mathrm{cm}$ for a foil thickness of 30 microns.

The resulting overall residual resistivity $\rho_{4 \cdot 2}$ and the $R R R$ values for the various annealing times appear in the last two columns of Tables VII(a) and VII(b) and in Figures 1 and 2. Mean values are in good agreement with experimental data. Values corrected for size effect are also included in Table IV.

Under given annealing conditions the RRR of a 200 microns thick foil is determined by the diffusion rate of iron up to an annealing time of approximately

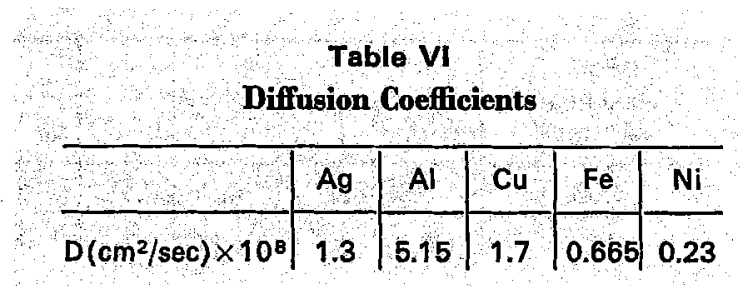


Table VII

Calculated Increase in Resistance, $\mu \Omega \mathrm{cm} \times 10^{4}$, at $1000^{\circ} \mathrm{C}$ as a Function of Annealing Time

(a) Foil Thickness 200 Microns

\begin{tabular}{|c|c|c|c|c|c|c|c|}
\hline Time, hours & $\mathrm{Ag}$ & Al & $\mathrm{Cu}$ & $\mathrm{Fe}$ & Size Effect & Total Increase & RRR \\
\hline 0 & 5 & 13.0 & 2.9 & 142 & 1.7 & \pm 45 & 140 \\
\hline 1 & 5 & 0.24 & 0.95 & 71. & 1.7 & \pm 19.6 & 291 \\
\hline 2 & 5 & 0.005 & 0.38 & 44 & 1.7 & \pm 13 & 451 \\
\hline 5 & 5 & - & 0.026 & 10 & 1.7 & \pm 4.6 & 1352 \\
\hline 8 & 5 & 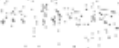 & 0.0017 & 2.4 & 1.7 & \pm 2.6 & 2555 \\
\hline 10 & 5 & 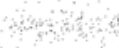 & - & 0.93 & 1.7 & $7.6 \pm 2.2$ & 3026 \\
\hline 16 & 5 & & - & 0.05 & 1.7 & $6.75 \pm 2.0$ & 3407 \\
\hline 24 & 5 & & - & 0.001 & 1.7 & $6.701 \pm 2.0$ & 3432 \\
\hline 32 & 5 & & & & 1.7 & $6.70 \pm 2.0$ & 3433 \\
\hline
\end{tabular}

(b) Foil Thickness 30 Microns

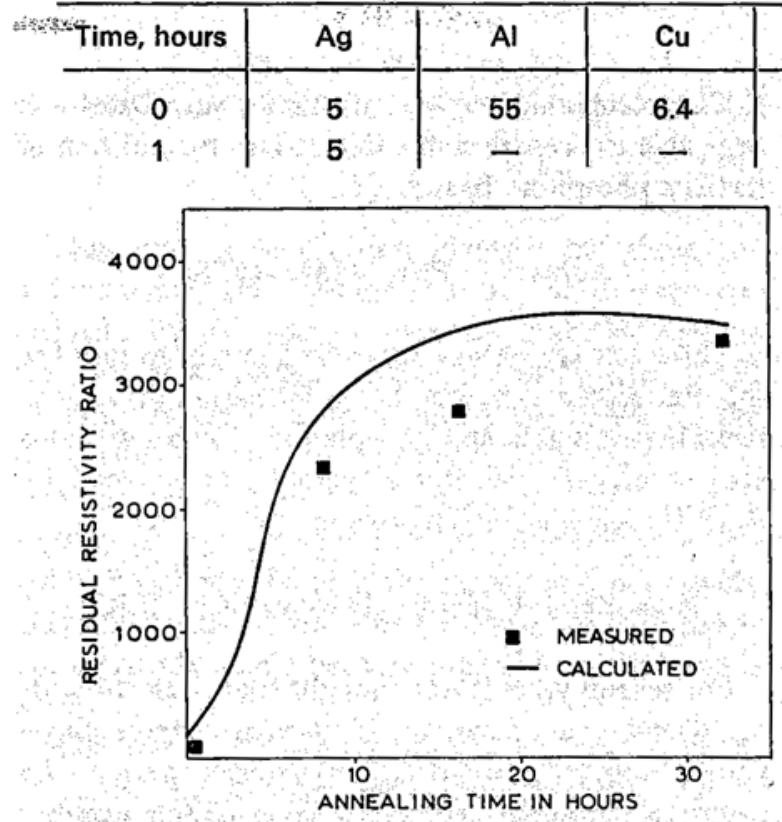

Fig. 1 Foil 200 microns thick, annealed at $1000^{\circ} \mathrm{C}$

8 hours. At longer annealing times the residual resistivity ratio is governed by the amount of silver and the size effect. Due to shorter diffusion times for the 30 microns foil, very brief annealing times suffice for the residual resistivity ratio to be determined by the amount of silver and the size effect.

Further increases in the residual resistivity ratio or purity of gold can only be achieved by the elimination of silver, for example by annealing in a chlorine atmosphere. Thereafter, the RRR is likely to be almost exclusively influenced by the size effect.

\section{Acknowledgements}

The authors wish to thank the Federal Ministry of Research and Technology for their financial support of the investigation reported in this paper.

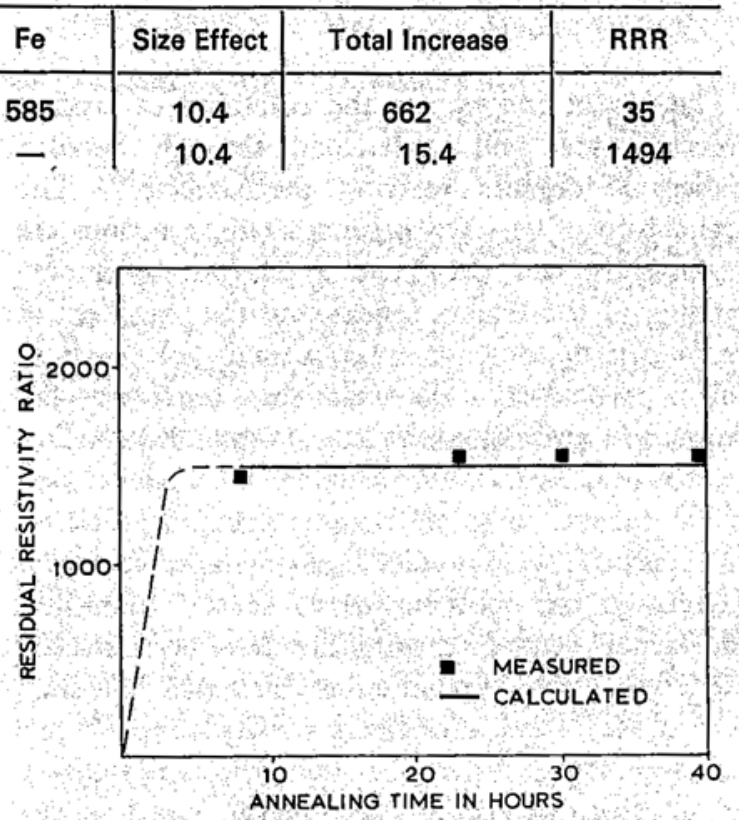

Fig. 2 Foil 30 microns thick, annealed at $1000^{\circ} \mathrm{C}$

\section{References}

1 J. S. Fritz and W. G. Millen, Talanta, 1971, 18, (3), 323 2 L. L. Kocheva and R. Gecheva, ibid, 1973, 20, (9), 910

3 R. Dybczynski and H. Maleszewska, Analyst, 1969, 94, (1120), 527

4 Z. Marczenko, K. Kasiura and M. Krasiejko, Z. Anal. Chem., 1971, 256, (5), 375

5 V. Lenher and C. H. Kao, F. Phys. Chem., 1926, 30, 126

6 B. F. Rimmer, Chem. \& Ind., 1974, (2), 63

7 D. F. C. Morris and M. A. Khan, Talanta, 1968, 15, (11), 1301

8 Gmelins Handbuch, Band Gold, Verlag Chemie, 1954

$9 \mathrm{~J}$. O. Linde, "Elektrische Widerstandseigenschaften der verdünnten Legierungen des Kupfers, Silbers und Goldes", Diss. Lund, 1939

10 W. Jost, "Diffusion", Darmstadt, 1957, 55

11 Landold-Börnstein, Band II, Teil 5b, 1968

12 F. Dworschak, W. Sassin, J. Wick and J. Wurm, Jül575-FN, KFA Jülich, 1969 